\title{
Tingkat Partisipasi Petani Hutan dalam Program Pengelolaan Hutan Bersama Masyarakat (PHBM) Perhutani
}

\author{
ADI WINATA ${ }^{1}$, ERNIK YULIANA ${ }^{2}$ \\ 1,2 Fakultas MIPA Universitas Terbuka, Jl. Cabe Raya Pondok Cabe, Pamulang, Tangerang Selatan 15418 \\ email: ${ }^{1}$ adit@ut.ac.id, ${ }^{2}$ ernik@ut.ac.id
}

\begin{abstract}
Collaborative Forest Management Program (PHBM) is formed by Perhutani for more involving community in forest management in Java. The active participation of forest farmers in the PHBM program is the key factor in achieving PHBM program. This paper analyse characteristics influence to the level of forest farmer participation in PHBM program. Located in the Buniwangi Village, District of Palabuhanratu, Sukabumi, research based on a quantitative survey with descriptive and regression analysis. Most of the forest farmers have participation in PHBM planning meetings, meetings of implementation, and evaluation of PHBM meeting. Age of forest farmers have significanly influence to farmers' participation in the planning and evaluation of PHBM program.
\end{abstract}

Key words: participation, forest farmers, PHBM.

\begin{abstract}
Abstrak. Program Pengelolaan Hutan Bersama Masyarakat (PHBM) dibentuk oleh Perhutani untuk lebih melibatkan masyarakat dalam mengelola hutan di Jawa. Partisipasi aktif petani hutan dalam program PHBM menjadi kunci utama dalam pencapaian tujuan program PHBM. Tulisan ini menganalisis pengaruh karakteristik petani hutan terhadap tingkat partisipasinya dalam program PHBM. Berlokasi di Desa Buniwangi, Kecamatan Palabuhanratu, Kabupaten Sukabumi, riset didasarkan pada survei kuantitatif dengan analisis deskriptif dan regresi. Sebagian besar petani hutan berpartisipasi dalam rapat perencanaan PHBM, rapat pelaksanaan, dan rapat evaluasi PHBM. Umur petani hutan berpengaruh signifikan terhadap partisipasi petani hutan dalam perencanaan dan evaluasi program PHBM.
\end{abstract}

Kata Kunci: partisipasi, petani hutan, PHBM.

\section{Pendahuluan}

Sumber daya hutan memiliki peran yang sangat penting dalam menjaga kelangsungan hidup manusia. Hutan dapat memberikan hasil kayu, nonkayu, perlindungan siklus air, penyerapan karbon, pemeliharaan keanekaragaman hayati dan habitat, serta berfungsi sebagai tujuan rekreasi.

Kebijakan pembangunan kehutanan yang bersifat sentralistik (terpusat dan dikelola oleh negara) dianggap oleh beberapa pihak tidak efektif dalam menjaga kawasan hutan (Jatminingsih, 2009: 1) dan hanya mengeksploitasi hasil hutan tanpa memperhatikan faktor sosial yang diakibatkannya. Dengan sistem sentralistik tersebut, masyarakat lokal kurang dilibatkan dalam pengelolaan hutan yang sesungguhnya merupakan bagian yang tidak dapat dipisahkan dari kehidupan mereka. Oleh karena itu, pendekatan yang dilakukan dalam pengelolaan hutan harus memperhatikan keberlanjutan ekosistem hutan dan peduli dengan masyarakat di sekitar hutan. Salah satu pendekatan pengelolaan hutan yang mengusung semangat itu adalah Pengelolaan Hutan Bersama Masyarakat (PHBM).

Program PHBM dibentuk oleh Perhutani pada tahun 2001 melalui surat keputusan direksi Perum Perhutani No. 136/KPTS/DIR/2001 tentang Pengelolaan Sumberdaya Hutan Bersama Masyarakat (Andayani, 2005: 2). Program PHBM melibatkan masyarakat desa sekitar hutan untuk mengelola hutan dan diharapkan masyarakat mendapatkan keuntungan dari sistem PHBM (Affianto et al., 2005: 32).

Sebagai bentuk pengelolaan hutan kolaboratif, PHBM tidak akan berjalan tanpa kontribusi dalam merencanakan, melaksanakan, dan mengevaluasi program PHBM dari para penggunanya; dalam hal ini adalah personil dan organisasi Perhutani di satu pihak, dan para petani hutan di pihak yang lain. Munggoro dan Aliadi 
(1999: 33) menjelaskan bahwa partisipasi aktif para pengguna ini diperlukan agar suatu sistem pengelolaan sumber daya alam dapat bekerja dengan baik. Partisipasi petani hutan, dalam berbagai segi pelaksanaan PHBM, dengan demikian menduduki tempat yang penting bagi tercapainya tujuan pengelolaan hutan, khususnya tujuan-tujuan program PHBM Akadun (2011: 186) menambahkan bahwa partisipasi petani hutan dalam program PHBM adalah implementasi dari partisipasi vertikal yang mementingkan pembinaan hubungan agar dapat memberikan manfaat.

Tujuan penulisan artikel adalah mengidentifikasi karakteristik petani hutan yang mengelola lahan hutan dengan sistem PHBM; mengidentifikasi tingkat partisipasi petani hutan dalam program PHBM; dan menganalisis pengaruh karakteristik petani hutan terhadap tingkat partisipasinya dalam program PHBM. Kerangka berfikir penelitian disajikan pada Gambar 1. Semua variabel dalam kerangka berfikir penelitian diidentifikasi dan diuji dalam penelitian.

Rancangan penelitian yang mendasari penulisan artikel adalah explanatory research design. Populasi penelitian adalah semua petani hutan di Desa Buniwangi, Kecamatan Palabuhanratu, Kabupaten Sukabumi, berjumlah 3.000 orang. Teknik sampling untuk mendapatkan responden 50 orang menggunakan cluster random sampling berdasarkan lokasi lahan yang digarap oleh petani hutan. Sampel tersebut dianggap mewakili populasi, karena populasi mempunyai kondisi yang hampir seragam. Data yang dikumpulkan adalah data primer, berupa karakteristik petani hutan (individu dan sosial), dan tingkat partisipasi masyarakat dalam PHBM. Variabel bebas $(X)$ adalah karakteristik petani hutan, terdiri atas karakteristik individu dan sosial. Variabel bergantung $(Y)$ adalah tingkat partisipasi petani hutan dalam program PHBM, yaitu partisipasi dalam perencanaan kegiatan program PHBM $\left(Y_{1}\right)$, kehadiran petani hutan dalam rapat KTH $\left(Y_{2}\right)$, penanaman tanaman rendah $\left(\mathrm{Y}_{3}\right)$, dan evaluasi kegiatan PHBM $\left(\mathrm{Y}_{4}\right)$.

Pengumpulan data menggunakan metode survei, dengan menyebarkan kuesioner kepada para petani hutan, dan pengisian kuesionernya dibantu oleh enumerator dan peneliti. Pertanyaan dalam kuesioner berupa pertanyaan tertutup dan terbuka. Waktu pengambilan data penelitian adalah JuniAgustus 2010. Analisis data menggunakan anaisis deskriptif dan regresi berganda. Analisis deskriptif untuk menganalisis karakteristik petani hutan dan tingkat partisipasi petani hutan dalam program PHBM. Regresi berganda digunakan untuk menganalisis pengaruh karakteristik petani hutan terhadap tingkat partisipasinya dalam program PHBM.

\section{Karakteristik Petani Hutan}

Individu petani hutan mempunyai karakteristik yang khas di setiap wilayah hutan PHBM. Karakteristik tersebut ikut menentukan

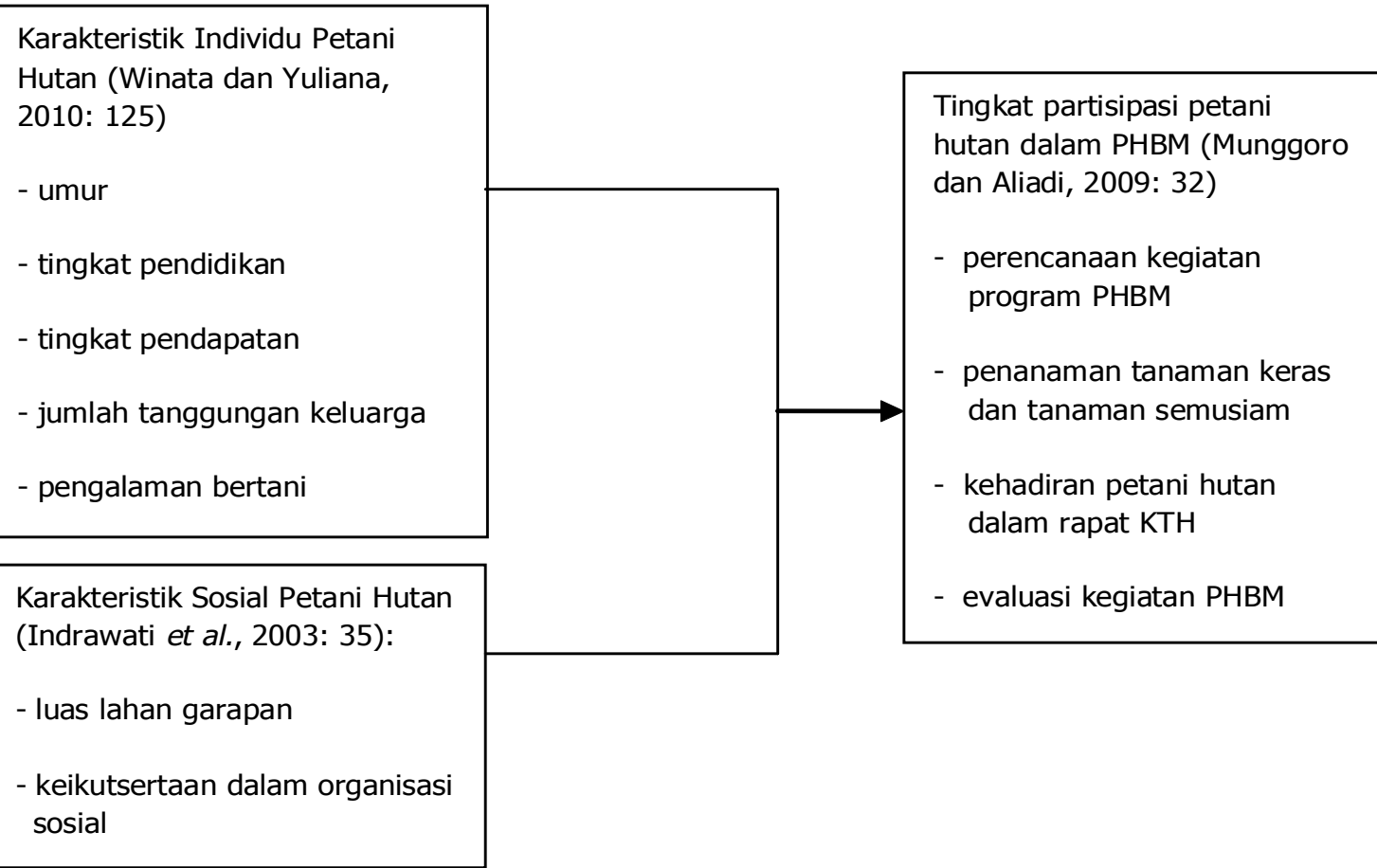

Gambar 1

Kerangka Berfikir Penelitian 
berjalannya program PHBM di suatu lahan hutan PHBM. Identifikasi karakteristik individu petani hutan menggunakan pendekatan sosiografis, yaitu dengan mengidentifikasi keadaan latar belakang petani hutan: umur, tingkat pendidikan, tingkat pendapatan, jumlah tanggungan keluarga, dan pengalaman bertani. Hasil identifikasi karakteristik individu petani hutan disajikan pada Tabel 1 .

Penggolongan umur petani hutan mengacu kepada hasil penelitian Yuliana (2007: 35), yaitu dewasa awal (18-35 tahun), dewasa pertengahan (36-50 tahun), dan dewasa akhir (> 50 tahun). Petani hutan sebanyak $60 \%$ mempunyai kategori umur dewasa akhir (> 50 tahun). Pada kisaran umur tersebut, petani hutan mencapai kematangan dalam bertani karena sudah ditekuni sejak usia muda, dan termasuk umur produktif (Masjud, 2000: 29). Akan tetapi pada golongan umur dewasa akhir, petani hutan sulit menerima/ mengadopsi kemajuan teknologi baru, misalnya alat komunikasi dan alat pertanian yang menggunakan mesin.

Seperti halnya golongan petani lainnya, petani hutan sebanyak $84 \%$ mempunyai tingkat pendidikan yang rendah (SD). Dalam berusahatani, petani hutan tidak berbekal pendidikan formal, tetapi mereka hanya berbekal pengalaman bertani yang sudah ditekuni sejak usia muda. Akan tetapi, tingkat pendidikan formal yang rendah tidak menghalangi petani hutan untuk menimba ilmu guna kemajuan mereka terutama dalam menggarap lahan Perhutani. Tingkat pendidikan yang rendah berdampak pada tingkat pengetahuan petani hutan. Menurut hasil penelitian Winata dan Yuliana (2011: 130), tingkat pengetahuan masyarakat petani/nelayan berhubungan dengan perannya dalam suatu program kegiatan.

Petani hutan menggarap lahan Perhutani dengan model pengelolaan hutan bersama masyarakat (PHBM). Jenis tanaman yang diperbolehkan oleh Perhutani untuk ditanam di lahannya adalah tanaman pokok hutan, tanaman buah, tanaman palawija, dan tanaman rendah di bawah tegakan. Dari tanaman-tanaman tersebut para petani hutan mendapatkan bagi hasil dari Perhutani. Akan tetapi, dari bagi hasil tersebut para petani hutan masih mempunyai tingkat pendapatan yang rendah $(72 \%)$, dengan rata-rata pendapatan Rp 665.800,-. Tingkat pendapatan tersebut sudah mengalami peningkatan dibandingkan dengan sebelum mereka menggarap lahan Perhutani, dengan rata-rata pendapatan Rp 377.000,-. Rata-

Tabel 1

Karakteristik Individu Petani Hutan

\begin{tabular}{|c|c|c|c|}
\hline No. & Karakteristik Petani Hutan (X) & Frekuensi & Persentase (\%) \\
\hline & Karaktersitik Individu Petani Hutan $\left(\mathrm{X}_{1}\right)$ & & \\
\hline \multirow[t]{5}{*}{1} & $\operatorname{Umur}\left(\mathrm{X}_{11}\right)$ & & \\
\hline & a. Dewasa awal ( $<35$ tahun) & 2 & 4 \\
\hline & b. Dewasa pertengahan (36-50 tahun) & 18 & 36 \\
\hline & c. Dewasa akhir (> 50 tahun) & 30 & 60 \\
\hline & Total & 50 & 100 \\
\hline \multirow[t]{5}{*}{2} & Tingkat Pendidikan $\left(\mathrm{X}_{12}\right)$ & & \\
\hline & a. Dasar (SD) & 42 & 84 \\
\hline & b. Menengah (SMP-SMA) & 8 & 16 \\
\hline & c. Tinggi (universitas) & 0 & 0 \\
\hline & - & 50 & 100 \\
\hline \multirow[t]{4}{*}{3} & Tingkat pendapatan $\left(\mathrm{X}_{13}\right)$ & & \\
\hline & a. Rendah & 36 & 72 \\
\hline & b. Tinggi & 14 & 28 \\
\hline & Total & 50 & 100 \\
\hline \multirow[t]{5}{*}{4} & Jumlah tanggungan keluarga $\left(\mathrm{X}_{14}\right)$ & & \\
\hline & a. Kecil (<3 orang) & 8 & 16 \\
\hline & b. Sedang (4-5 orang) & 24 & 48 \\
\hline & c. Besar ( $\geq 6$ orang) & 18 & 36 \\
\hline & Total & 50 & 100 \\
\hline \multirow[t]{5}{*}{5} & Pengalaman bertani $\left(\mathrm{X}_{15}\right)$ & & \\
\hline & a. Baru (0-5 tahun) & 4 & 8 \\
\hline & b. Sedang (6-10 tahun) & 18 & 36 \\
\hline & C. Lama (> 10 tahun) & 28 & 56 \\
\hline & Total & 50 & 100 \\
\hline
\end{tabular}


rata pendapatan petani hutan bersumber dari tanaman palawija (Rp 377.000,-), tanaman buah (Rp 339.600,-), tanaman di bawah tegakan (Rp $224.400,-)$, dan tanaman pokok (Rp 37.200,-).

Rendahnya tingkat pendapatan petani hutan, disebabkan mereka belum dapat memetik hasil dari tanaman pokok. Dari hasil wawancara dengan petani hutan, didapatkan bahwa hanya 5 orang petani yang sudah dapat menikmati hasil dari tanaman pokok, itu pun belum maksimum. Padahal, dari tanaman pokok inilah jumlah penghasilan yang diharapkan lebih besar daripada hasil dari tanaman lainnya. Tanaman pokok yang mereka tanam belum memasuki usia panen, sehingga belum dapat dinikmati hasilnya.

Jumlah tanggungan keluarga petani kebanyakan berkisar 4-5 orang, yang terdiri atas anak yang masih belum mandiri dan isteri. Dengan pendapatan rata-rata $\mathrm{Rp} 665.800$,- untuk menanggung 4-5 orang anggota keluarga, maka dapat diperkirakan kualitas hidup keluarga petani hutan masih jauh dari kemapanan.

Pengalaman bertani yang dimiliki petani hutan paling banyak adalah lebih dari 10 tahun (28\%). Menurut Affianto et al. (2005: 2), salah satu tujuan PHBM adalah meningkatkan peran dan tanggung jawab masyarakat desa sekitar hutan terhadap keberlanjutan, fungsi, dan manfaat sumber daya hutan. Dengan bekal pengalaman bertani lebih dari 10 tahun, diharapkan petani dapat memanfaatkan lahan Perhutani dengan baik sehingga tujuan PHBM dapat tercapai dari sisi ekologi dan ekonomi.

Karakteristik sosial petani hutan adalah ciriciri kehidupan petani hutan yang berhubungan dengan kehidupan sosialnya. Identifikasi karakteristik sosial petani hutan berguna untuk mengetahui pihak-pihak yang berhubungan dengan petani. Hasil identifikasi karakteristik sosial petani hutan disajikan pada Tabel 2.
Petani hutan paling banyak (58\%) mempunyai lahan garapan yang sempit ( $d^{\prime \prime} 0,25$ hektar). Hal ini sesuai dengan pendapat Affianto et al. (2005: 8), bahwa petani hutan umumnya menggarap lahan Perhutani dalam program PHBM seluas $0,25-0,5$ hektar. Lahan tersebut dibagi menjadi beberapa blok. Survei penelitian dilakukan pada 7 blok, yaitu Ciguplek, Cilewi, Cigupuk, Cisaat, Cempaka, Pasir Mangir, dan Datar Jati. Keadaan blok lahan garapan rata-rata miring, hanya 2 blok lahan yang datar.

Pada lahan Perhutani yang termasuk dalam kategori sempit tersebut, petani melakukan aktivitas pertanian sekaligus menjaga kelestarian tanaman pokok, karena hal itu merupakan salah satu kewajiban petani. Hal ini sesuai dengan pendapat Sudjito dan Megawati (2010: 60), bahwa kewajiban petani hutan adalah melindungi sumber daya hutan dan memberi kontribusi faktor produksi sesuai dengan kemampuannya. Kewajiban tersebut memang cukup berat bagi petani, karena petani juga perlu meningkatkan pendapatan mereka di samping harus menjaga kelestarian tanaman pokok. Oleh karena itu, sudah selayaknya petani mendapatkan bagi hasil yang memadai dari Perhutani, yang selama ini masih dalam perdebatan tentang proporsi pembagian hasil tersebut.

Keikutsertaan petani hutan dalam organisasi sosial termasuk sedang (56\%), dengan mengikuti paling banyak 2 organisasi. Kelompok yang paling banyak diikuti oleh petani hutan adalah pengajian dan kelompok tani hutan (KTH). Keikutsertaan petani dalam organisasi sosial berguna untuk menambah wawasan mereka melalui diskusi atau penyuluhan dari pihak Perhutani atau pihak lain. Melalui organisasi sosial inilah, petani dapat mengembangkan dirinya untuk menerima pengetahuan dan informasi baru guna pengelolaan lahan Perhutani.

Tingkat Partisipasi Petani Hutan dalam

Tabel 2

Karakteristik Sosial Petani Hutan

\begin{tabular}{|c|c|c|c|}
\hline & Karakteristik Sosial Petani Hutan $\left(\mathbf{X}_{2}\right)$ & Frekuensi & Persentase (\%) \\
\hline \multirow[t]{5}{*}{1} & Luas lahan garapan $\left(\mathrm{X}_{21}\right)$ & & \\
\hline & a. Sempit ( $\leq 0,25$ hektar) & 29 & 58 \\
\hline & b. Sedang $(0,3-0,5$ hektar $)$ & 13 & 26 \\
\hline & c. Luas (lebih dari 0,5 hektar) & 8 & 16 \\
\hline & Total & 50 & 100 \\
\hline \multirow[t]{5}{*}{2} & Keikutsertaan dalam organisasi sosial $\left(\mathrm{X}_{22}\right)$ & & \\
\hline & a. Rendah ( $0-1$ organisasi) & 20 & 40 \\
\hline & b. Sedang (2 organisasi) & 28 & 56 \\
\hline & c. Tinggi ( $\geq 3$ organisasi) & 2 & 4 \\
\hline & Total & 50 & 100 \\
\hline
\end{tabular}




\section{Program PHBM}

Pengukuran tingkat partisipasi pada penelitian ini mengacu kepada pendapat Indrawati et al. (2003: 34) bahwa partisipasi merupakan suatu proses yang melibatkan seluruh pihak terkait secara aktif dalam rangkaian kegiatan, mulai dari kehadiran petani dalam rapat kelompok tani hutan, kehadiran dalam rapat perencanaan, dan sumbangan pemikiran dalam perencanaan. Pada kegiatan pelaksanaan, partisipasi yang diukur adalah petani menanam tanaman pokok dan tanaman semusim pada lahan garapan, sedangkan dalam kegiatan evaluasi adalah kehadiran petani pada rapat evaluasi dan sumbangan pemikiran dalam rapat evaluasi. Hasil identifikasi tingkat partisipasi petani hutan dalam program PHBM disajikan pada Tabel 3.

Tingkat partisipasi petani hutan dalam perencanaan program masih rendah, yaitu sebanyak $62 \%$ tidak hadir dalam rapat perencanaan atau hadir dalam rapat tetapi sedikit sekali memberikan sumbangan pemikiran, rata-rata hanya 1 sumbangan pemikiran. Rapat perencanaan program PHBM membahas kegiatan-kegiatan yang akan dilakukan dalam kelangsungan PHBM, misalnya pohon atau tanaman apa saja yang boleh ditanam di lahan Perhutani. Jika petani hadir dalam rapat perencanaan, maka mereka dapat memberikan pendapat tentang program PHBM yang akan mereka jalankan. Jadi ide pelaksanaan program PHBM tidak hanya berasal dari Perhutani. Oleh karena itu, partisipasi petani hutan dalam perencanaan program perlu ditingkatkan melalui sosialisasi atau penyuluhan secara rutin dari pihak Perhutani. Dengan demikian salah satu prinsip PHBM yaitu perencanaan program yang bersifat

Tabel 3

Tingkat Partisipasi Petani Hutan dalam Program PHBM

\begin{tabular}{|c|c|c|c|}
\hline No. & $\begin{array}{c}\text { Tingkat Partisipasi Petani Hutan dalam Program } \\
\text { PHBM Perhutani }(Y)\end{array}$ & Frekuensi & $\begin{array}{l}\text { Persentase } \\
(\%)\end{array}$ \\
\hline \multirow[t]{5}{*}{1} & $\begin{array}{l}\text { Tingkat partisipasi petani hutan dalam perencanaan } \\
\text { program PHBM }\left(\mathrm{Y}_{1}\right)\end{array}$ & & \\
\hline & $\begin{array}{l}\text { a. Hadir dalam rapat perencanaan } 1-5 \text { kali dan } \\
\text { memberikan } 1 \text { sumbangan pemikiran }\end{array}$ & 31 & 62 \\
\hline & $\begin{array}{l}\text { b. Hadir dalam rapat perencanaan }>5 \text { kali dan } \\
\text { memberikan } 1 \text { sumbangan pemikiran }\end{array}$ & 14 & 28 \\
\hline & $\begin{array}{l}\text { c. Hadir dalam rapat perencanaan }>5 \text { kali dan } \\
\text { memberikan } 2 \text { sumbangan pemikiran }\end{array}$ & 5 & 10 \\
\hline & Total & 50 & 100 \\
\hline \multirow[t]{5}{*}{2} & Tingkat kehadiran petani dalam rapat kelompok $\left(\mathrm{Y}_{2}\right)$ & & \\
\hline & $\begin{array}{l}\text { a. Hadir dalam rapat kelompok 1-5 kali dan memberikan } 1 \\
\text { sumbangan pemikiran }\end{array}$ & 35 & 70 \\
\hline & $\begin{array}{l}\text { b. Hadir dalam rapat kelompok }>5 \text { kali dan memberikan } 1 \\
\text { sumbangan pemikiran }\end{array}$ & 7 & 14 \\
\hline & $\begin{array}{l}\text { c. Hadir dalam rapat perencanaan }>5 \text { kali dan } \\
\text { memberikan } 2 \text { sumbangan pemikiran }\end{array}$ & 8 & 16 \\
\hline & Total & 50 & 100 \\
\hline \multirow[t]{5}{*}{3} & $\begin{array}{l}\text { Sumbangan kegiatan: menanami lahan dengan tanaman } \\
\text { semusim }\left(\mathrm{Y}_{3}\right)\end{array}$ & & \\
\hline & a. Menanami lahan dengan 1-2 tanaman rendah & 17 & 34 \\
\hline & b. Menanami lahan dengan 3-4 tanaman rendah & 19 & 38 \\
\hline & c. Menanmi lahan dengan $>4$ tanaman rendah & 14 & 28 \\
\hline & Total & 50 & 100 \\
\hline \multirow[t]{5}{*}{4} & $\begin{array}{l}\text { Tingkat partisipasi petani dalam evaluasi program PHBM } \\
\left(\mathrm{Y}_{4}\right)_{i}\end{array}$ & & \\
\hline & $\begin{array}{l}\text { a. Hadir dalam rapat evaluasi tetapi tidak memberikan } \\
\text { sumbangan pemikiran }\end{array}$ & 31 & 62 \\
\hline & $\begin{array}{l}\text { b. Hadir dalam rapat evaluasi dan memberikan } 1 \\
\text { sumbangan pemikiran }\end{array}$ & 24 & 48 \\
\hline & $\begin{array}{l}\text { c. Hadir dalam rapat evaluasi dan memberika n2 } \\
\text { sumbangan pemikiran }\end{array}$ & 5 & 10 \\
\hline & Total & 50 & 100 \\
\hline
\end{tabular}

Sumber: hasil pengolahan data 2010 
partisiapatif dan fleksibel sesuai dengan karakteristik wilayah (Affianto et al., 2005: 7) juga perlu ditingkatkan pencapaiannya.

Sebanyak 38\% petani hutan mempunyai tingkat partisipasi dalam perencanaan program PHBM termasuk kategori sedang sampai tinggi. Mereka menghadiri rapat perencanaan rata-rata lebih dari 5 kali dan memberikan sumbangan pemikiran lebih dari satu. Tabel 4 menyajikan beberapa alasan yang mendasari kehadiran mereka dalam rapat perencanaan program PHBM.

Berdasarkan data pada Tabel 4, motivasi kehadiran petani dalam perencanaan program banyak didorong oleh keinginan untuk berpartisipasi dalam penyusunan program PHBM. Perencanaan program PHBM meliputi arah dan pelaksanaan PHBM, jenis tanaman yang boleh ditanam, jarak tanam, dan materi lainnya. Dengan hadir di dalam rapat perencanaan program PHBM, maka petani dapat memberikan sumbangan pemikiran agar program dapat dilaksanakan oleh semua pihak. Menurut Affianto et al. (2005: 2), perencanaan program PHBM harus dilakukan secara partisipatif dengan melibatkan para petani dan fleksibel sesuai karakteristik wilayah.

Program PHBM di Desa Buniwangi termasuk berhasil mendorong partisipasi petani dalam perencanaan, meskipun tingkatnya masih rendah. Hal ini terbukti dari beberapa sumbangan pemikiran yang telah diberikan dalam rapat perencanaan program. Salah satunya adalah perjuangan mereka dalam mengusulkan tanaman karet untuk ditanam di lahan mereka. Dengan beberapa kali usulan dalam rapat dan argumentasi yang jelas, akhirnya petani dibolehkan menanam karet, yang sebelumnya tidak diizinkan oleh Perhutani. Beberapa sumbangan pemikiran petani dalam perencanaan program disajikan pada Tabel 5.

Dalam pelaksanaan program PHBM, ada dua indikator pengukuran tingkat partisipasi petani hutan, yaitu tingkat kehadirannya dalam $\mathrm{KTH}$, dan kegiatan yang dilakukan petani dalam menanam tanaman semusim, tanaman masyarakat, dan

Tabel 4

Motivasi Kehadiran Petani Hutan dalam Rapat Perencanaan Program PHBM

\begin{tabular}{|ll|}
\hline No. & Motivasi Kehadiran Petani dalam Rapat Perencanaan Program PHBM \\
\hline 1 & Mengetahui dan berpartisipasi dalam membuat perencanaan program PHBM \\
2 & Mengetahui acuan dan arah dalam pelaksanaan PHBM \\
3 & Merasa sabagai petani penggarap/KTH \\
4 & Merasa ikut tumpang sari di lahan Perhutani \\
5 & Berpartisipasi dalam perumusan program PHBM \\
6 & Ingin terlibat dalam perencanaan program PHBM \\
7 & Mengetahui cara menghijaukan hutan dan tata cara menanam milik petani \\
\hline
\end{tabular}

Tabel 5

Contoh Sumbangan Pemikiran Petani Hutan dalam Perencanaan Program

\begin{tabular}{|c|c|}
\hline No. & Sumbangan Pemikiran Petani Hutan dalam Perencanaan Program \\
\hline 1 & $\begin{array}{l}\text { Jenis tanaman yang ditanam tidak hanya khusus tanaman keras saja, akan tetapi juga harus } \\
\text { disertai dengan tanaman masyarakatnya, seperti tanaman karet }\end{array}$ \\
\hline 2 & $\begin{array}{l}\text { Menentukan jenis tanaman, baik tanaman keras/pokok maupun tanaman masyarakatnya, } \\
\text { Ingin lebih bebas dalam menggap lahan }\end{array}$ \\
\hline 3 & Jarak tanam tanaman pokok \\
\hline 4 & Usulan jarak tanam $6 \times 2$ meter, usulan pengadaan bibit untuk program PHBM \\
\hline 5 & $\begin{array}{l}\text { Usulan tanaman pisang dan karet, pengadaan bibit baik tanaman pokok maupun tanaman } \\
\text { sela }\end{array}$ \\
\hline 6 & Harus ada kesepakatan antara perhutani dengan para penggarap/KTH \\
\hline 7 & Jelasnya tata batas antar lahan garapan anggota KTH dan jenis tanaman \\
\hline 8 & $\begin{array}{l}\text { Dalam program PHBM harus ada tanaman sela tidak hanya tanaman pokok, untuk jenis } \\
\text { tanaman sela tidak hanya tanaman buah tetapi juga karet }\end{array}$ \\
\hline 9 & Melestarikan hutan, meningkatan ekonomi, penguatan kelembagaan \\
\hline 10 & Mengusulkan menanam karet dan sengon/albasia \\
\hline
\end{tabular}


tanaman palawija di sela-sela tanaman pokok.

Kehadiran petani dalam rapat KTH masih tergolong rendah, dengan alasan utama adalah ada kesibukan lain. Hal ini mengindikasikan bahwa salah satu prinsip PHBM yang dikemukakan oleh Affianto et al. (2005: 7) belum tercapai. Dari hasil penelitian ini, terlihat bahwa petani hutan belum terbiasa dengan diskusi kelompok yang diadakan oleh KTH. Padahal di dalam KTH, dapat dibahas tentang pelaksanaan program PHBM agar lebih menguntungkan bagi petani. Selanjutnya, harus ada program yang dapat mendorong petani hutan untuk hadir di dalam rapat KTH.

Dari hasil wawancara dengan beberapa petani hutan yang hadir dalam rapat $\mathrm{KTH}$, dapat digali beberapa hal yang berkaitan dengan rapat $\mathrm{KTH}$, di antaranya adalah materi yang dibahas dalam rapat tersebut. Tabel 6 menyajikan beberapa materi yang dibahas dalam rapat KTH.
Berdasarkan data pada Tabel 6, dapat dilihat bahwa bahwa materi yang dibahas dalam rapat KTH cukup komprehensif, mulai dari aspek kelembagaan, teknis penanaman tanaman pokok, dan tanaman semusim, hingga pengaturan bagi hasil antara petani dan Perhutani. Dengan pembahasan materi yang komprehensif, maka program Perhutani dapat dilaksanakan dengan pendekatan kerja sama kelembagaan dengan hak dan kewajiban yang jelas. Menurut Jaya (2009: 1), komitmen petani untuk bekerja sama dengan mengelola lahan perhutani menggunakan model kemitraan diharapkan muncul rasa memiliki dan bertanggung jawab terhadap pengelolaan hutan dan pelestariannya sehingga dapat memberikan manfaat bagi masyarakat sendiri.

Dalam pelaksanaan program PHBM, petani hutan menanami lahan Perhutani dengan tanaman pokok dan tanaman semusim. Tanaman pokok

Tabel 6

\section{Materi yang Dibahas dalam Rapat KTH}

\begin{tabular}{|c|c|}
\hline No. & Materi yang Dibahas dalam Rapat KTH \\
\hline 1 & $\begin{array}{l}\text { Tentang kelompok atau kelembagaan dan menentukan jenis tanaman yang akan ditanam } \\
\text { di lahan PHBM }\end{array}$ \\
\hline 2 & Tentang penguatan kelembagaan KTH, Pengelolaan hutan yang baik \\
\hline 3 & MoU bagi hasil, Jarak tanam \\
\hline 4 & Manfaat hutan dan bagi hasil \\
\hline 5 & Jenis tanaman pokok, jenis tanaman sela, hak dan kewajiban \\
\hline 6 & Pengelolaan hutan, cara penanaman tanaman, pemberantasan hama \\
\hline 7 & $\begin{array}{l}\text { Bagaimana caranya agar hutan yang sudah gundul kembali hijau, bagaimana cara melestarikan } \\
\text { hutan }\end{array}$ \\
\hline 8 & Kewajiban kita selaku penggarap dilahan perhutani agar patuh pada aturan \\
\hline 9 & $\begin{array}{l}\text { Bahwa setiap orang yang menggarap harus berkelompok, bagi para pencuri kayu harus } \\
\text { di hukum }\end{array}$ \\
\hline 10 & Penanaman tanaman keras/pokok, kelompok, pengelolaan hutan yang lestari \\
\hline 11 & Agar mengikuti aturan organisasi, disiplin dalam berkelompok \\
\hline
\end{tabular}

Tabel 7

Jenis Tanaman di Lahan Perhutani

\begin{tabular}{|lllll|}
\hline No. & Tanaman Pokok & Tanaman Masyarakat (Kayu) & Tanaman Semusim & Tanaman Palawija \\
\hline & & & & \\
1 & Mahoni & Durian & Pisang & Padi \\
2 & Pinus & Pete & Trubuk & Cabe \\
3 & Sungke & Jengkol & Lada & Kacang \\
4 & Jati & Albasia & Tisuk & Jagung \\
5 & Ki Kaya & Karet & Kencur & Ketimun \\
6 & - & Sengon & Jahe & - \\
7 & - & Kecapi & Ubi jalar & - \\
8 & - & Nangka & Kunyit & - \\
9 & - & Jambu & Kapulaga & - \\
10 & - & Alpukat & Singkong & - \\
11 & - & Mangga & - & - \\
\hline
\end{tabular}


adalah tanaman keras yang jenisnya sudah ditentukan oleh Perhutani, sedangkan tanaman semusim adalah jenis tanaman yang ditanam di sela-sela tanaman pokok. Berdasarkan hasil wawancara dengan petani hutan, saat ini para petani sudah diijinkan menanam beragam jenis tanaman semusim. Sebelumnya, Perhutani hanya mengijinkan petani untuk menanam tanaman semusim dengan jenis tertentu. Tabel 7 menyajikan jenis tanaman pokok, tanaman semusim, dan tanaman palawija yang ditanam oleh petani di lahan Perhutani.

Partisipasi petani dalam menanam tanaman sela termasuk termasuk dalam kategori sedang, yaitu menanam 3-4 tanaman semusim dan ada lebih dari 5 aktivitas di lahan. Jenis tanaman sela yang banyak ditanam oleh petani adalah tanaman masyarakat dan tanaman semusim, karena tanaman tersebut tidak membutuhkan perawatan yang intensif. Untuk tanaman palawija, termasuk jarang ditanam oleh petani, karena menanam tanaman palawija membutuhkan keahlian dan keterampilan khusus dalam merawatnya.

Tingkat partisipasi petani dalam evaluasi program PHBM sebanyak $62 \%$ adalah hadir dalam rapat evaluasi tetapi tidak memberikan sumbangan pemikiran. Kegiatan evaluasi program diperlukan untuk menilai hasil pelaksanaan sebuah program. Dengan dilakukan evaluasi, dapat diketahui apakah sebuah program sudah berjalan dengan baik atau belum. Program PHBM dirancang untuk melibatkan petani secara partisipatif mulai dari perencanaan sampai evaluasi program. Dengan melibatkan petani secara aktif dalam program PHBM diharapkan terjadi perubahan pola pikir pada aparat Perum Perhutani dari birokratis, sentralistik, kaku, dan ditakuti menjadi fasilitator, fleksibel, akomodatif, dan dicintai (Affianto et al., 2005: 2).

Berdasarkan hasil penelitian tentang partisipasi petani dalam evaluasi program, implikasinya adalah harus ada program untuk mendorong keterlibatan petani secara aktif dalam evaluasi program. Dengan demikian, Perhutani dapat mendengar secara langsung masukan dari petani guna perbaikan program di masa mendatang. Rendahnya keterlibatan petani dalam evaluasi program, mengindikasikan masih ada kesenjangan antara petani dengan Perhutani. Tujuan PHBM untuk menjadikan Perhutani sebagai fasilitator yang dicintai oleh petani belum maksimum.

\section{Pengaruh Karakteristik Petani Hutan (X) terhadap Keikutsertaan Petani Hutan dalam Perencanaan Program PHBM $\left(\mathbf{Y}_{1}\right)$}

Hasil analisis regresi variabel karakteristik petani hutan $(X)$ dan keikutsertaan petani hutan dalam perencanaan program PHBM $\left(Y_{1}\right)$ disajikan pada Tabel 8. Berdasarkan hasil regresi, karakteristik petani hutan yang berpengaruh nyata terhadap keikutsertaan petani hutan dalam perencanaan program PHBM (pada $\alpha=0,1$ ) adalah umur petani hutan $\left(\mathrm{X}_{1}\right)$. Artinya, semakin tinggi umur petani hutan, maka keikutsertaan petani hutan dalam perencanaan program PHBM juga meningkat. Hal ini sesuai dengan pendapat Indrawati et al. (2003: 34), bahwa partisipasi masyarakat ditentukan oleh variabel demografi seperti umur, status perkawinan dan pendidikan.

Berdasarkan hasil regresi pada Tabel 8, dapat disusun persamaan regresi untuk pengaruh karakteristik individu dan karakteristik sosial petani hutan terhadap keikutsertaan petani hutan dalam

\section{Tabel 8 \\ Hasil Regresi Variabel Karakteristik Petani Hutan (X) dan Keikutsertaan Petani Hutan dalam Perencanaan Program PHBM $\left(Y_{1}\right)$}

\begin{tabular}{|lcccc|}
\hline $\begin{array}{l}\text { Tingkat Kehadiran } \\
\text { Petani Hutan dalam Rapat } \\
\text { Kelompok Tani }\left(\mathbf{Y}_{\mathbf{1}}\right)\end{array}$ & Koefisien & Standard Error & $\begin{array}{c}\text { Nilai t } \\
\text { hitung }\end{array}$ & Nilai P \\
\hline Intercept & 1,394 & 0,479 & 2,912 & 0,006 \\
Umur $\left(\mathrm{X}_{11}\right)$ & 0,009 & 0,181 & 0,047 & 0,962 \\
Tingkat pendidikan $\left(\mathrm{X}_{12}\right)$ & 0,257 & 0,242 & 1,059 & 0,295 \\
Tingkat pendapatan $\left(\mathrm{X}_{13}\right)$ & 0,194 & 0,178 & 1,093 & 0,281 \\
Jumlah tanggungan keluarga $\left(\mathrm{X}_{14}\right)$ & 0,070 & 0,121 & 0,581 & 0,565 \\
Pengalaman bertani $\left(\mathrm{X}_{15}\right)$ & 0,171 & 0,162 & 1,057 & 0,296 \\
Luas lahan garapan $\left(\mathrm{X}_{21}\right)$ & $-0,040$ & 0,119 & $-0,340$ & 0,736 \\
Keikutsertaan petani hutan & & & & \\
dalam organisasi sosial $\left(\mathrm{X}_{22}\right)$ & $-0,255$ & 0,164 & $-1,552$ & 0,128 \\
\hline
\end{tabular}


merencanakan program PHBM, yaitu $Y_{1}=2,34+$ $0,43 \mathrm{X}_{11}{ }^{*}+0,20 \mathrm{X}_{12}-0,18 \mathrm{X}_{13}+0,14 \mathrm{X}_{14}-0,25 \mathrm{X}_{15}-$ $0,05 X_{21}-0,26 X_{22}$.

Umur petani hutan $\left(X_{1}\right)$ yang didominasi oleh kategori umur dewasa akhir ( $>50$ tahun) berpengaruh secara signifikan terhadap keikutsertaan petani hutan dalam perencanaan program PHBM $\left(Y_{1}\right)$. Artinya, semakin bertambah umur petani hutan, maka keikutsertaan petani hutan dalam program PHBM semakin tinggi. Petani hutan yang sudah berumur lebih dari 50 tahun, mempunyai pengalaman bertani yang lebih lama daripada petani yang berumur lebih muda. Pengalaman bertani tersebut berguna dalam menyusun program PHBM terutama dalam menentukan jenis tanaman yang akan ditanam di sela-sela tanaman pokok. Oleh karena itu, harus selalu diadakan sosialisasi tentang program PHBM kepada seluruh petani hutan agar keikutsertaan mereka dalam merencanakan program PHBM dapat meningkat. Peningkatan keikutsertaan petani hutan dalam merencanakan program PHBM adalah salah satu prinsip yang ingin dicapai dalam pelaksanaan PHBM (Affianto et al., 2005: 2), yaitu perencanaan program PHBM dilakukan secara partisipatif dan fleksibel seusai dengan karakteristik wilayah.

\section{Pengaruh Karakteristik Petani Hutan (X) terhadap Kehadiran Petani Hutan dalam Rapat Kelompok Tani Hutan $\left(\mathbf{Y}_{2}\right)$}

Hasil analisis regresi variabel karakteristik petani hutan (X) dan kehadiran petani hutan dalam rapat kelompok $\left(\mathrm{Y}_{2}\right)$ disajikan pada Tabel 9. Berdasarkan hasil regresi, karakteristik petani hutan tidak ada yang berpengaruh nyata terhadap variabel tingkat kehadiran petani hutan dalam rapat kelompok (pada $\alpha=0,1$ ). Berdasarkan hasil regresi pada Tabel 9, dapat disusun persamaan regresi untuk pengaruh karakteristik individu dan karakteristik sosial petani hutan terhadap tingkat kehadiran petani hutan dalam rapat kelompok, yaitu $\mathrm{Y}_{2}=1,39+0,01 \mathrm{X}_{11} *+0,26 \mathrm{X}_{12}+0,19 \mathrm{X}_{13}+0,07 \mathrm{X}_{14}$ $+0,17 X_{15}-0,04 X_{21}-0,26 X_{22}$.

Meskipun hasil analisis regresi memberikan hasil bahwa karakteristik petani hutan tidak ada yang berpengaruh secara signifikan terhadap tingkat kehadiran petani hutan dalam rapat kelompok, tetapi dapat dilihat bahwa tingkat pendidikan petani hutan mempunyai koefisien pengaruh yang besar $(0,257)$ dibandingkan variabel lainnya. Artinya, tingkat pendidikan petani hutan memberikan pengaruh kepada tingkat kehadiran petani dalam rapat kelompok tetapi tidak signifikan. Sebagian besar petani hutan berpendidikan SD, jadi mereka tidak memahami pentingnya kehadiran dalam rapat kelompok. Oleh karena itu, perlu diadakan sosialisasi dari pihak Perhitani atau ketua kelompok tani hutan tentang pentingnya hadir dalam rapat kelompok kepada para petani.

\section{Pengaruh Karakteristik Petani Hutan (X) terhadap Kegiatan Petani Hutan dalam Menanami Lahan dengan Tanaman $\operatorname{Rendah}\left(\mathbf{Y}_{3}\right)$}

Hasil analisis regresi variabel karakteristik petani hutan (X) dan kegiatan petani hutan dalam menanami lahan dengan tanaman rendah $\left(Y_{3}\right)$ disajikan pada Tabel 10. Berdasarkan hasil regresi, karakteristik petani hutan yang berpengaruh nyata terhadap variabel kegiatan petani hutan dalam menanami lahan dengan tanaman semusim (pada

Tabel 9

Hasil Regresi Variabel Karakteristik Petani Hutan (X) dan Kehadiran Petani Hutan dalam Rapat Kelompok Tani $\left(Y_{2}\right)$

\begin{tabular}{|lllll|}
\hline $\begin{array}{l}\text { Tingkat Kehadiran } \\
\text { Petani Hutan dalam Rapat } \\
\text { Kelompok Tani }\left(\mathbf{Y}_{2}\right)\end{array}$ & Koefisien & Standard Error & $\begin{array}{c}\text { Nilai t } \\
\text { hitung }\end{array}$ & Nilai P \\
\hline Intercept & 1,394 & 0,479 & 2,912 & 0,006 \\
Umur $\left(\mathrm{X}_{11}\right)$ & 0,009 & 0,181 & 0,047 & 0,962 \\
Tingkat pendidikan $\left(\mathrm{X}_{12}\right)$ & 0,257 & 0,242 & 1,059 & 0,295 \\
Tingkat pendapatan $\left(\mathrm{X}_{13}\right)$ & 0,194 & 0,178 & 1,093 & 0,281 \\
Jumlah tanggungan keluarga $\left(\mathrm{X}_{14}\right)$ & 0,070 & 0,121 & 0,581 & 0,565 \\
Pengalaman bertani $\left(\mathrm{X}_{15}\right)$ & 0,171 & 0,162 & 1,057 & 0,296 \\
Luas lahan garapan $\left(\mathrm{X}_{21}\right)$ & $-0,040$ & 0,119 & $-0,340$ & 0,736 \\
Keikutsertaan petani hutan & & & & \\
dalam organisasi sosial $\left(\mathrm{X}_{22}\right)$ & $-0,255$ & 0,164 & $-1,552$ & 0,128 \\
\hline
\end{tabular}

Keterangan: $\alpha=0,1 ; \mathrm{R}^{2}=0,129$ 
$\alpha=0,1)$ adalah luas lahan garapan yang dimiliki oleh petani, tetapi pengaruhnya adalah negatif. Artinya, semakin luas lahan yang dimiliki oleh petani hutan, maka tingkat penanaman tanaman semusim pada lahan garapan semakin rendah. Hasil ini sesuai dengan pendapat Indrawati et al. (2003: 34), bahwa partisipasi petani dalam suatu kegiatan dipengaruhi oleh kondisi fisik lapangan (kelerengan tanah dan luas lahan). Dari hasil ini, dapat ditarik makna bahwa petani dengan luas lahan garapan yang sempit tertarik untuk menanam tanaman semusim.

Berdasarkan hasil regresi pada Tabel 10, dapat disusun persamaan regresi untuk pengaruh karakteristik individu dan karakteristik sosial petani hutan terhadap kegiatan petani hutan dalam menanami lahan garapan dengan tanaman rendah, yaitu $Y_{3}=2,69+0,26 X_{11} *-0,22 X_{12}-0,16 X_{13}+$ $0,13 X_{14}+0,03 X_{15}-0,30 X_{21} *-0,15 X_{22}$.

Kegiatan petani hutan menanam tanaman rendah adalah untuk meningkatkan pendapatan sambil menunggu panen dari tanaman pokok. Menurut Andayani dan Sembodo (2004: 16), pada program PHBM, petani hutan dapat menggarap lahan Perhutani dengan sistem usahatani menggunakan pola campuran (tumpang sari) antara tanaman pokok dan tanaman rendah (semusim). Pada dasarnya, konsep tersebut dikembangkan dengan tujuan untuk meningkatkan produktivitas, efisiensi lahan usaha, dan

Tabel 10

Hasil Regresi Variabel Karakteristik Petani Hutan (X) dan Kegiatan Petani Hutan dalam Menanami Lahan dengan Tanaman Rendah $\left(Y_{3}\right)$

\begin{tabular}{|lllll|}
\hline $\begin{array}{l}\text { Tingkat Kehadiran } \\
\text { Petani Hutan dalam Rapat } \\
\text { Kelompok Tani }\left(\mathbf{Y}_{3}\right)\end{array}$ & Koefisien & Standard Error & $\begin{array}{c}\text { Nilai t } \\
\text { hitung }\end{array}$ & Nilai P \\
\hline Intercept & 2,685 & 0,469 & 5,724 & 0,000 \\
Umur $\left(X_{11}\right)$ & 0,255 & 0,177 & 1,440 & 0,157 \\
Tingkat pendidikan $\left(X_{12}\right)$ & $-0,219$ & 0,238 & $-0,922$ & 0,362 \\
Tingkat pendapatan $\left(X_{13}\right)$ & $-0,160$ & 0,174 & $-0,919$ & 0,363 \\
Jumlah tanggungan keluarga $\left(X_{14}\right)$ & 0,129 & 0,118 & 1,089 & 0,282 \\
Pengalaman bertani $\left(X_{15}\right)$ & 0,034 & 0,159 & 0,215 & 0,831 \\
Luas lahan garapan $\left(X_{21}\right)$ & $-0,303 *$ & 0,116 & $-2,603$ & 0,013 \\
Keikutsertaan petani hutan & & & & \\
dalam organisasi sosial $\left(X_{22}\right)$ & $-0,152$ & 0,161 & $-0,941$ & 0,352 \\
\hline
\end{tabular}

Keterangan: $\alpha=0,1 ; \mathrm{R}^{2}=0,349$

Sumber: hasil pengolahan data penelitian, 2010

Tabel 11

Hasil Regresi Variabel Karakteristik Petani Hutan (X) dan Partisipasi Petani dalam Evaluasi Program Perhutani $\left(\mathbf{Y}_{4}\right)$

\begin{tabular}{|lllll|}
\hline $\begin{array}{l}\text { Tingkat Kehadiran } \\
\text { Petani Hutan dalam Rapat } \\
\text { Kelompok Tani }\left(\mathrm{Y}_{3}\right)\end{array}$ & Koefisien & Standard Error & $\begin{array}{c}\text { Nilai t } \\
\text { hitung }\end{array}$ & Nilai P \\
\hline Intercept & 0,110 & 0,623 & 0,176 & 0,861 \\
Umur $\left(X_{11}\right)$ & $0,649 *$ & 0,235 & 2,757 & 0,009 \\
Tingkat pendidikan $\left(X_{12}\right)$ & 0,320 & 0,316 & 1,013 & 0,317 \\
Tingkat pendapatan $\left(X_{13}\right)$ & $-0,382$ & 0,232 & $-1,650$ & 0,106 \\
Jumlah tanggungan keluarga $\left(X_{14}\right)$ & $0,370^{*}$ & 0,157 & 2,352 & 0,023 \\
Pengalaman bertani $\left(X_{15}\right)$ & $-0,147$ & 0,211 & $-0,696$ & 0,490 \\
Luas lahan garapan $\left(X_{21}\right)$ & $-0,068$ & 0,155 & $-0,439$ & 0,663 \\
Keikutsertaan petani hutan & & & & \\
dalam organisasi sosial $\left(X_{22}\right)$ & $-0,046$ & 0,214 & $-0,214$ & 0,832 \\
\hline
\end{tabular}

Keterangan: $\alpha=0,1 ; R^{2}=0,315$

Sumber: hasil pengolahan data penelitian, 2010 
meningkatkan nilai ekonomi per satuan luas tertentu. Akan tetapi sistem tumpang sari tersebut hanya menarik bagi petani yang mempunyai lahan garapan yang sempit. Petani hutan yang mempunyai lahan garapan yang luas lebih tertarik untuk menanami lahannya dengan tanaman pokok, karena keuntungan lebih besar tetapi membutuhkan waktu yang lama.

\section{Pengaruh Karakteristik Petani Hutan (X) terhadap Partisipasi Petani dalam Evaluasi Program Perhutani $\left(\mathrm{Y}_{4}\right)$}

Hasil analisis regresi variabel karakteristik petani hutan $(X)$ dan partisipasi petani hutan dalam evaluasi program Perhutani $\left(\mathrm{Y}_{4}\right)$ disajikan pada Tabel 11. Berdasarkan hasil regresi, karakteristik petani hutan yang berpengaruh nyata terhadap partisipasi petani hutan dalam evaluasi program Perhutani (pada $\alpha=0,1$ ) adalah umur petani hutan dan jumlah tanggungan keluarga. Arti yang pertama adalah semakin bertambah umur petani hutan, maka partisipasi petani hutan dalam evaluasi program Perhutani semakin meningkat, karena mereka mempunyai pengalaman yang lebih banyak dibandingkan dengan petani hutan yang berumur lebih muda. Arti yang kedua adalah semakin banyak jumlah tanggungan keluarga, maka partisipasi petani hutan dalam evaluasi program Perhutani semakin meningkat. Petani hutan yang mempunyai jumlah tanggungan keluarga yang besar, punya keinginan kuat untuk meningkatkan pendapatannya, sehingga mereka tertarik untuk memberikan evaluasi program Perhutani agar dapat memberi masukan guna peningkatan pendapatan petani hutan dalam rangka memenuhi kebutuhan keluarga. Hasil penelitian ini sesuai dengan pendapat (Indrawati et al., 2003: 35), bahwa partisipasi petani dalam suatu kegiatan sangat dipengaruhi oleh umur dan tingkat pendapatan.

Berdasarkan hasil regresi pada Tabel 11, dapat disusun persamaan regresi untuk pengaruh karakteristik individu dan karakteristik sosial petani hutan terhadap partisipasi petani hutan dalam evaluasi program Perhutani yang dilakukan bersama dengan Perhutani, yaitu $Y_{4}=0,11+$ $0,65 X_{11} *+0,32 X_{12}-0,38 X_{13}+0,37 X_{14}^{4} *$ $0,15 X_{15}-0,07 X_{21}{ }^{*}-0,05 X_{22}$.

Di dalam rapat evaluasi program Perhutani dibahas tentang hasil pelaksanaan program PHBM. Dari hasil pelaksanaan tersebut, petani hutan dan pihak Perhutani dapat menilai kualitas pelaksanaannya dan memberikan masukan. Untuk memberikan masukan kepada Perhutani, memang diperlukan petani hutan yang dituakan. Partisipasi petani hutan dalam evaluasi program Perhutani sangat penting karena hasil evaluasi digunakan untuk merencanakan program kerja selanjutnya dan mengidentifikasi kelemahan-kelemahan yang menghambat pelaksanaan program yang telah berjalan. Menurut Affianto et al. (2005: 3), evaluasi program Perhutani harus dilakukan bersama stakholders yang berkepentingan dengan program PHBM. Evaluasi yang dilakukan bersama antara petani dan pihak Perhutani akan memberikan manfaat bagi kedua belah pihak.

\section{Kesimpulan dan Saran}

Petani hutan dalam penelitian ini paling banyak mempunyai umur lebih dari 50 tahun dengan tingkat pendidikan SD. Tingkat pendapatan petani masih tergolong rendah, dengan jumlah tanggungan keluarga 4-6 orang. Pengalaman bertani yang dimiliki petani hutan adalah lebih dari 10 tahun, dengan menggarap lahan sempit ( $d^{\prime \prime} 0,25$ hektar).

Tingkat partisipasi petani hutan dalam perencanaan program masih rendah, sementara dalam pelaksanaan program termasuk kategori sedang, dan dalam evaluasi program masih rendah. Tingkat keberhasilan program PHBM dalam menjaga kelestarian tanaman pokok termasuk sedang, dalam mencegah pencurian kayu termasuk kategori sedang, dan dalam meningkatkan pendapatan petani termasuk kategori tinggi.

Umur petani hutan berpengaruh signifikan terhadap keikutsertaan petani dalam perencanaan dan evaluasi program PHBM. Luas lahan garapan yang dimiliki oleh petani berpengaruh negatif secara signifikan terhadap kegiatan petani hutan dalam menanami lahan dengan tanaman semusim. Semakin luas lahan yang dimiliki oleh petani hutan, maka tingkat penanaman tanaman semusim pada lahan garapan semakin rendah.

Dengan masih rendahnya tingkat partisipasi petani dalam perencanaan dan evaluasi program, maka diperlukan sebuah program yang dapat mendorong petani untuk lebih aktif terlibat dalam perencanaan dan evaluasi. Caranya adalah dengan pendekatan persuasif kepada petani agar petani lebih sering menghadiri rapat kelompok. Di dalam rapat kelompok dapat disampaikan materi yang dapat memotivasi petani untuk lebih aktif terlibat dalam perencanaan dan evaluasi.

\section{Daftar Pustaka}

Affianto, A., Djatmiko, W.A., Riyanto, S., Hermawan, T.T. (2005). 'Analisis Biaya dan Pendapatan dalam Pengelolaan PHBM', Bogor: LATIN.

Akadun (2011). Revitalisasi Forum Musrenbang Sebagai Wahana Partisipasi Masyarakat dalam Perencanaan Pembangunan Daerah, MIMBAR, Vol. XXVII No. 2 (Desember 2011): 183-192 'Terakreditasi' SK Dikti No. 64a/DIKTI/ Kep/ 241. 
ADI WINATA DKK. Tingkat Partisipasi Petani Hutan dalam Program Pengelolaan Hutan Bersama Masyarakat..

Andayani, W. (2005). 'Ekonomi Agroforestri', Yogyakarta: Debut Press.

Andayani, W. dan Sembodo, L.P. (2004). Analisis Sistem Bagi Hasil Pola Pengusahaan Hutan Program PHBM di KPH Pemalang, Jurnal Hutan Rakyat VI (1) 2004: 13-26.

Indrawati, D.R., Irawan, E., Haryanti, N., Yuliantoro, D. (2003). Partisipasi Masyarakat dalam Upaya Rehabilitasi Lahan dan Konservasi Tanah (RLKT), Jurnal Pengelolaan DAS Surakarta IX (1) 2003: 30-44.

Jatminingsih, T. (2009). Karakteristik Lingkungan, Karakteristik Petani Pesanggem, dan Peran Masyarakat Lokal dalam PHBM KPH Kendal. Tugas Akhir. Jurusan Perencanaan Wilayah dan Kota, Fakultas Teknik Universitas Diponegoro. Semarang: Universitas Diponegoro.

Jaya, D.E. (2009). Peran Polres Ciamis dalam Penanggulangan Illegal Logging di Wilayah Ciamis Melalui Program Pengelolaan Hutan Bersama Masyarakat (PHBM).http:// 125.161.190.253/lontar/opac/themes/libriptik/ detail.jsp? id=205 (Diakses 17 April 2010).

Masjud, Y.I. (2000). Kajian Karakteristik dan
Dampak Lingkungan Kegiatan Petani Sekitar Hutan, Southeast Asia Policy Research Working Paper No. 10. Bogor: ICRAF Southeast Asia.

Munggoro, D.W. dan Aliadi, A. (1999). 'Community Forestry dalam Konteks Perubahan Institutsi Kehutanan (Kembalikan hutan kepada rakyat)'. Bogor: Pustaka LATIN.

Sudjito, B. dan Megawati, E. (2010). Dimensi Hukum Normatif Pengelolaan Hutan Bersama Masyarakat dalam Kerangka Penanggulangan Illegal Loging dan Pelestarian Sumberdaya Hutan, Prosiding Seminar Nasional BSS 7 FMIPA Universitas Brawijaya. Malang: Universitas Brawijaya.

Winata dan Yuliana (2010). Peran Masyarakat Pesisir dalam Penerapan Strategi Konservasi Sumber Daya Laut (Kasus di Kelurahan Palabuhanratu, Kecamatan Palabuhanratu, Kabupaten Sukabumi), Jurnal Matematika, Sains, dan Teknologi 11 (2): 122-132.

Yuliana, E. (2007). Hubungan Karakteristik Mahasiswa dengan Persepsinya terhadap Tugas Akhir Program, Jurnal Pendidikan 8 (1): 32-50. 